\title{
The learning curve in endoscopic endonasal resection of craniopharyngiomas
}

\author{
Varun R. Kshettry, MD,,3 Hyunwoo Do, MD, ${ }^{1}$ Khaled Elshazly, MD, ${ }^{1,4}$ Christopher J. Farrell, MD, ${ }^{1}$ \\ Gurston Nyquist, MD, ${ }^{2}$ Marc Rosen, MD, ${ }^{1,2}$ and James J. Evans, MD ${ }^{1,2}$ \\ Departments of ${ }^{1}$ Neurological Surgery and ${ }^{2}$ Otolaryngology, Thomas Jefferson University, Philadelphia, Pennsylvania; \\ ${ }^{3}$ Department of Neurological Surgery, Neurological Institute, Cleveland Clinic, Cleveland, Ohio; and ${ }^{4}$ Department of Neurological \\ Surgery, Ain Shams University Hospital, Cairo, Egypt
}

OBJECTIVE There is a paucity of literature regarding the learning curve associated with performing endoscopic endonasal cranial base surgery. The purpose of this study was to determine to what extent a learning curve might exist for endoscopic endonasal resection in cases of craniopharyngiomas.

METHODS A retrospective review was performed for all endoscopic endonasal craniopharyngioma resections performed at Thomas Jefferson University from 2005 to 2015. To assess for a learning curve effect, patients were divided into an early cohort (2005-2009, $n=20)$ and a late cohort $(2010-2015, n=23)$. Preoperative demographics, clinical presentation, imaging characteristics, extent of resection, complications, tumor control, and visual and endocrine outcomes were obtained. Categorical variables and continuous variables were compared using a 2-sided Fisher's exact test and t-test, respectively.

RESULTS Only the index operation performed at the authors' institution was included. There were no statistically significant differences between early and late cohorts in terms of patient age, sex, presenting symptoms, history of surgical or radiation treatment, tumor size or consistency, hypothalamic involvement, or histological subtype. The rate of gross-total resection (GTR) increased over time from $20 \%$ to $65 \%(p=0.005)$, and the rate of subtotal resection decreased over time from $40 \%$ to $13 \%(p=0.078)$. Major neurological complications, including new hydrocephalus, meningitis, carotid artery injury, or stroke, occurred in 6 patients (15\%) (8 complications) in the early cohort compared with only $1(4 \%)$ in the late cohort $(p=0.037)$. CSF leak decreased from $40 \%$ to $4 \%(p=0.007)$. Discharge to home increased from $64 \%$ to $95 \%$ $(p=0.024)$. Visual improvement was high in both cohorts ( $88 \%$ [early cohort] and $81 \%$ [late cohort]). Rate of postoperative panhypopituitarism and permanent diabetes insipidus both increased from $50 \%$ to $91 \%(p=0.005)$ and $32 \%$ to $78 \%$ $(p=0.004)$, which correlated with a significant increase in intentional stalk sacrifice in the late cohort (from $0 \%$ to $70 \%, p$ $<0.001)$.

CONCLUSIONS High rates of near- or total resection and visual improvement can be achieved using an endoscopic endonasal approach for craniopharyngiomas. However, the authors did find evidence for a learning curve. After 20 cases, they found a significant decrease in major neurological complications and significant increases in the rates of GTR rate and discharge to home. Although there was a large decrease in the rate of postoperative CSF leak over time, this was largely attributable to the inclusion of very early cases prior to the routine use of vascularized nasoseptal flaps. There was a significant increase in new panhypopituitarism and diabetes insipidus, which is attributable to increase rates of intentional stalk sacrifice.

https://thejns.org/doi/abs/10.3171/2016.9.FOCUS16292

KEY WORDS craniopharyngioma; endonasal; endoscopic; transsphenoidal; transnasal; endocrine; vision; outcome

ABBREVIATIONS ACTH = adrenocorticotropin hormone; BMI = body mass index; $\mathrm{DI}$ = diabetes insipidus; $\mathrm{GTR}$ = gross-total resection; NTR = near-total resection; STR = subtotal resection. 
$\mathrm{H}$ ARVEY Cushing has described craniopharyngiomas as the "most forbidding of the intracranial tumors." ${ }^{2,6,10}$ In his published series of 2000 intracranial operations, there were approximately 92 craniopharyngiomas, 14 of which were treated via a transsphenoidal route. ${ }^{1,5}$ Cushing experienced a $14 \%$ mortality rate and virtually abandoned the transsphenoidal route in favor of the subfrontal route for these tumors. ${ }^{5,6}$ The introduction of the operating microscope, in addition to intravenous cortisone and antibiotic therapy, significantly reduced the perioperative mortality rate in the 1950s. Nonetheless, the intimate relation of these tumors with the hypothalamus, optic apparatus, internal carotid arteries, and surrounding perforators still resulted in considerable perioperative morbidity. The introduction of the expanded endoscopic transnasal approaches in the early 2000s has reinvigorated interest in surgically treating craniopharyngiomas

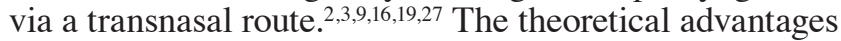
of the transnasal route include greater visualization of the optic chiasm perforators, direct visualization of bilateral hypothalami, and the elimination of brain retraction. A recent systematic review found significantly greater rates of gross-total resection (GTR), improved visual outcome, and reduction of seizures, at the expense of significantly increased postoperative CSF leaks. ${ }^{15}$ However, significant selection bias exists in such a comparison, and larger series of transcranial operations for craniopharyngiomas suggested that better outcomes can be obtained at more experienced centers. ${ }^{7,11,12,23}$

Despite the growing experience in endoscopic endonasal techniques, the treatment of craniopharyngiomas via this route still requires significant technical skill and experience. There is a paucity of literature regarding the learning curve associated with treating these uncommon tumors via the endonasal approach. In fact, very little published documentation exists regarding the learning curve associated with endonasal cranial base cases in general. 17,18,24,30,33 The purpose of the present study was to determine if, and to what extent, a learning curve exists for the endoscopic transnasal resection of craniopharyngiomas.

\section{Methods \\ Study Population}

The study population consisted of all cases from November 2005 to December 2015 treated at the authors' institution of patients who had a histological diagnosis of craniopharyngioma and who were treated via an endoscopic transnasal approach. Endoscopic skull base cases were initially performed at our institution starting in 2004. To assess for a learning curve effect, craniopharyngioma cases were divided into an early cohort (2005-2009) and a late cohort (2010-2015).

All patients underwent a preoperative biochemical endocrinological evaluation including morning (7-8 AM) serum cortisol or adrenocorticotropin hormone (ACTH) stimulation test, ACTH growth hormone, insulin-like growth factor-1, prolactin, thyroid-stimulating hormone, free T4, luteinizing hormone, follicle-stimulating hormone, and testosterone. Although some patients had a component of increased thirst and urination preoperatively, a diagno- sis of preoperative diabetes insipidus (DI) was considered only if desmopressin was started preoperatively. All patients underwent postoperative endocrine testing in the follow-up period, and postoperative endocrine deficits were diagnosed by the presence of corresponding low serum values or if the patient already required replacement hormonal therapy.

All patients underwent pre- and postoperative visual acuity and Humphrey visual field testing performed by an independent ophthalmologist. Visual outcome was graded as improved, stable, or worse. Body mass index (BMI) was recorded just prior to surgery and at the most recent follow-up time point.

All patients were evaluated preoperatively by an otolaryngologist, and all underwent thin-slice CT scanning of the sinus and a volumetric contrast-enhanced MRI, unless medically contraindicated. The hypothalamus was considered involved if the tumor displaced or invaded the medial or inferior hypothalamus on at least one side. Extent of resection on postoperative MRI was defined as GTR, near-total resection (NTR) if $>95 \%$ of the tumor was removed, and subtotal resection (STR) if $<95 \%$ of the tumor was removed. MRI assessment of extent of resection was performed by an independent neuroradiologist. Recurrence and progression were defined as the appearance of new tumor after a previous GTR or the growth of residual tumor after NTR or STR, respectively. This retrospective study was approved by the Thomas Jefferson Institutional Review Board.

\section{Operative Technique}

A 2-surgeon, 4-handed technique with binostril access was employed. The surgical technique has been previously described. ${ }^{8}$ A few nuances are noted as follows. Middle turbinates were lateralized rather than resected in all patients. The bone of the tuberculum sella was removed laterally to include the lateral tubercular strut to provide wide access to bilateral medial opticocarotid recesses. The superior intercavernous sinus was controlled either by direct electrocautery or by injection of hemostatic agents into the sinus. Aggressive central debulking was performed in all cases to allow greater ease in mobilization of the tumor capsule. Reconstruction of the skull base varied in earlier cases but, around 2008, was standardized to a fascia lata inlay/onlay button graft as we have previously described, followed by a vascularized nasoseptal flap, synthetic dural sealant, and absorbable packing. ${ }^{2}$ Middle turbinates were medialized at the end of the procedure. No nonabsorbable materials, stents, or balloons were used. Lumbar drains were infrequently used, but were so used at the discretion of the treating surgeon. Antibiotic prophylaxis with a firstgeneration cephalosporin or vancomycin in the setting of penicillin allergy was administered within 1 hour prior to surgery and continued for 24 hours postoperatively.

\section{Statistical Analysis}

To compare the early and late cohort demographics, tumor characteristics, and outcomes, a 2-sided chi-square analysis was performed for categorical variables. For variables with counts fewer than 5, a 2-sided Fisher's exact test 
TABLE 1. Patient history and demographics in early and late cohorts

\begin{tabular}{|c|c|c|c|c|}
\hline History & Total & Early $(n=20)$ & Late $(n=23)$ & $p$ Value \\
\hline Mean age (range) & $42.3(14-74)$ & $44.9(19-74)$ & $40.0(14-65)$ & 0.309 \\
\hline \multicolumn{5}{|l|}{ Sex } \\
\hline Male & $25(58 \%)$ & $12(60 \%)$ & $13(57 \%)$ & 0.818 \\
\hline Female & $18(42 \%)$ & $8(40 \%)$ & $10(43 \%)$ & - \\
\hline \multicolumn{5}{|l|}{ Presenting symptoms } \\
\hline Vision loss & $43(100 \%)$ & $20(100 \%)$ & $23(100 \%)$ & - \\
\hline Headache & $21(49 \%)$ & $8(40 \%)$ & $13(57 \%)$ & 0.280 \\
\hline Endocrinopathy* & $13(30 \%)$ & $4(20 \%)$ & $9(39 \%)$ & 0.203 \\
\hline Weight gain & $3(7 \%)$ & 0 & $3(13 \%)$ & 0.236 \\
\hline Fatigue & $6(14 \%)$ & $1(5 \%)$ & $5(22 \%)$ & 0.192 \\
\hline Memory/cognitive & $2(5 \%)$ & $2(10 \%)$ & 0 & 0.210 \\
\hline \multicolumn{5}{|l|}{ Prior surgery } \\
\hline Transcranial & $8(19 \%)$ & $5 \dagger(25 \%)$ & $3(13 \%)$ & 0.440 \\
\hline Transsphenoidalł & $4(9 \%)$ & $2(10 \%)$ & $2(9 \%)$ & - \\
\hline Prior radiotherapy & $4(9 \%)$ & $3(15 \%)$ & $1(4 \%)$ & 0.324 \\
\hline \multicolumn{5}{|l|}{ Prior intracystic therapy } \\
\hline Ommaya reservoir & $1(2 \%)$ & 0 & $1(4 \%)$ & - \\
\hline Intracystic therapy & 0 & 0 & 0 & - \\
\hline
\end{tabular}

was performed. A 2-sided t-test was used for all continuous variables. $\mathrm{p}<0.05$ was considered significant.

\section{Results}

A total of 49 endoscopic endonasal resections were performed in 43 patients from November 2005 to December 2015 . Only the index endoscopic endonasal operation performed at our institution was included in the final analysis, leaving 43 patients/operations for analysis.

The mean age was 42.3 years overall and was not significantly different between early and late cohorts (44.9 vs 40.0 years, respectively; $p=0.309$ ) (Table 1$)$. There was a slight male predominance (58\%) overall, and it was similar between cohorts. All patients presented with some degree of visual loss attributable to the tumor. Other common presenting symptoms included headache (49\%), endocrinopathy (30\%), fatigue (14\%), weight gain (7\%), and memory or cognitive impairment (5\%). There were no significant differences in presentation between cohorts.

Twelve patients (28\%) had prior surgery for resection of craniopharyngioma. Of these 12 patients, 8 had a prior transcranial approach and 4 had a prior transsphenoidal approach. There were no significant differences between the 2 cohorts. Prior Ommaya reservoir placement was performed only in 1 patient, and no patient had previously received intracystic therapy. Four patients (9\%) had a history of radiotherapy to treat the craniopharyngioma.

Median tumor diameter in the early cohort was $29 \mathrm{~mm}$ compared with $30 \mathrm{~mm}$ in the late cohort (Table 2). The majority $(67 \%)$ of tumors were both solid and cystic. A minority of patients had predominantly cystic $(21 \%)$ or solid (12\%) tumors. Tumor consistency was similar between cohorts. Most patients (88\%) had tumors involving the hypothalamus. The adamantinomatous histological sub-

TABLE 2. Preoperative MRI characteristics

\begin{tabular}{lcccc}
\hline \multicolumn{1}{c}{ Characteristic } & Total & Early $(\mathrm{n}=20)$ & Late $(\mathrm{n}=23)$ & $\mathrm{p}$ Value \\
\hline Max tumor diameter mean, median (range) in mm & $30.6,29(10-81)$ & $34.0,29(15-81)$ & $27.6,30(10-40)$ & 0.103 \\
\hline Tumor consistency* & & & & \\
\hline Solid & $5(12 \%)$ & $3(15 \%)$ & $2(9 \%)$ & 0.650 \\
\hline Cystic & $9(21 \%)$ & $4(20 \%)$ & $5(22 \%)$ & - \\
\hline Both & $29(67 \%)$ & $13(65 \%)$ & $16(70 \%)$ & 0.750 \\
\hline Hypothalamic involvement† & $38(88 \%)$ & $19(95 \%)$ & $19(83 \%)$ & 0.351 \\
\hline
\end{tabular}

* Tumor was graded as primarily cystic or solid if $>90 \%$ of the tumor was cystic or solid, respectively.

$\dagger$ Hypothalamic involvement was present if the tumor displaced or invaded the medial or inferior hypothalamus on at least one side. 


\section{TABLE 3. Surgical outcomes}

\begin{tabular}{|c|c|c|c|c|}
\hline Surgical Outcome & Total & $\begin{array}{c}\text { Early } \\
(n=20)\end{array}$ & $\begin{array}{l}\text { Late } \\
(n=23)\end{array}$ & $\begin{array}{c}\mathrm{p} \\
\text { Value }\end{array}$ \\
\hline \multicolumn{5}{|l|}{ Histological subtype* } \\
\hline Adamantinomatous & $29(67 \%)$ & $14(74 \%)$ & $15(65 \%)$ & 0.739 \\
\hline Papillary & $13(30 \%)$ & $5(26 \%)$ & $8(35 \%)$ & - \\
\hline \multicolumn{5}{|l|}{ Extent of resection† } \\
\hline STR & $11(26 \%)$ & $8(40 \%)$ & $3(13 \%)$ & 0.078 \\
\hline NTR (>95\%) & $13(30 \%)$ & $8(40 \%)$ & $5(22 \%)$ & 0.193 \\
\hline GTR & $19(44 \%)$ & $4(20 \%)$ & $15(65 \%)$ & 0.005 \\
\hline \multicolumn{5}{|l|}{ Complications } \\
\hline New hydrocephalus & $5(12 \%)$ & $4(20 \%)$ & $1(4 \%)$ & 0.167 \\
\hline Meningitis & $2(5 \%)$ & $2(10 \%)$ & 0 & 0.210 \\
\hline CSF leak & $9(21 \%)$ & $8(40 \%)$ & $1(4 \%)$ & 0.007 \\
\hline Hyponatremia & $1(2 \%)$ & 0 & $1(4 \%)$ & - \\
\hline Seizure & $1(2 \%)$ & 0 & $1(4 \%)$ & - \\
\hline Medical complicationsł & $6(14 \%)$ & $4(20 \%)$ & $2(9 \%)$ & 0.393 \\
\hline $\begin{array}{l}\text { Rhinological complica- } \\
\text { tions§ }\end{array}$ & $8(19 \%)$ & $4(20 \%)$ & $4(17 \%)$ & - \\
\hline Carotid artery injury & $1(2 \%)$ & $1(5 \%)$ & 0 & 0.465 \\
\hline Stroke & $1(2 \%)$ & $1(5 \%)$ & 0 & 0.465 \\
\hline Median length of stay (days) & 6 & 6 & 6 & - \\
\hline \multicolumn{5}{|l|}{ Discharge status $\mathbb{\|}$} \\
\hline Home & $30(83 \%)$ & $9(64 \%)$ & $21(95 \%)$ & 0.024 \\
\hline $\begin{array}{l}\text { Rehabilitation or nursing } \\
\text { facility }\end{array}$ & $6(17 \%)$ & $5(36 \%)$ & $1(5 \%)$ & - \\
\hline
\end{tabular}

* One patient did not have enough tissue to determine histological subtype. $\dagger$ As determined by postoperative MRI. Six patients had planned STR due to the nature of their tumor ( 3 underwent STR and 3 underwent NTR [> 95\%]). $\ddagger$ Deep vein thrombosis, pulmonary embolus $(n=2)$, urinary tract infection, thrombophlebitis requiring intravenous antibiotics, sepsis, and gastrointestinal bleed.

$\S$ Epistaxis, anterior septal perforation $(n=4)$, sinusitis $(n=2)$, and saddle nose deformity.

If Not available in 7 patients.

type was more common (67\%) than the papillary subtype $(30 \%)$ overall, but the distribution of histological subtypes between cohorts was similar.

The extent of resection was significantly different between early and late cohorts. Gross-total resection was achieved in $65 \%$ of cases in the late cohort compared with only $20 \%$ in the early cohort $(p=0.005)$ (Table 3$)$. Subtotal resection was performed in $40 \%$ of early cases compared with only $13 \%$ of late cases $(p=0.078)$.

Complications were more frequent in the early cohort (Table 3). A CSF leak occurred in 8 patients (40\%) in the early cohort compared with only $1(4 \%)$ in the late cohort $(\mathrm{p}=0.007)$. There was 1 carotid artery injury and 1 stroke (in the same patient) in the early cohort only. There were 2 cases of meningitis in the early cohort only. Major neurological complications including new hydrocephalus, meningitis, carotid artery injury, or stroke occurred in 6 patients (14\%) (8 complications) in the early cohort compared with only $1(4 \%)$ in the late cohort $(\mathrm{p}=0.037)$. Median length of stay was 6 days for both cohorts. However, there was a significant difference in discharge status
TABLE 4. Postoperative visual outcome*

\begin{tabular}{lcccc}
\hline Visual Outcome & Total & Early $(n=20)$ & Late $(n=23)$ & $p$ Value \\
\hline Improved & $31(84 \%)$ & $14(88 \%)$ & $17(81 \%)$ & 0.680 \\
\hline \multicolumn{1}{c}{ Normalized } & $9(24 \%)$ & $6(38 \%)$ & $3(14 \%)$ & - \\
\hline Stable & $5(14 \%)$ & $1(6 \%)$ & $4(19 \%)$ & - \\
\hline Worse & $1(3 \%)$ & $1(6 \%)$ & 0 & - \\
\hline
\end{tabular}

${ }^{*}$ Not available in 6 patients (14\%).

between cohorts. In the early cohort, only $64 \%$ of patients were discharged to home (as opposed to rehabilitation or nursing facility) compared with $95 \%$ in the late cohort ( $\mathrm{p}$ $=0.024$ ).

Visual outcome results were available in 37 patients and were similar between cohorts (Table 4). Overall, visual improvement was seen in $84 \%$ of patients. The overall rate of vision normalization was $24 \%$. Postoperative vision was stable in 5 patients (14\%) and worsened in $1(3 \%)$, with the single case of visual deterioration occurring in a patient in the early cohort.

Postoperative endocrinopathy was much more common in the late cohort, most likely a reflection of the more aggressive resection and greater proportion of infundibulum sacrifice (Table 5). New or worsening anterior pituitary endocrinopathy occurred in $5(28 \%)$ of 18 patients in the early cohort compared with $15(65 \%)$ of 23 in the late cohort ( $\mathrm{p}=0.017)$. Normal postoperative endocrine function was only achieved in 1 patient (4\%) in the late cohort compared with $5(28 \%)$ in the early cohort $(\mathrm{p}=0.070)$. New permanent DI was significantly more frequent in the late cohort $(61 \%$ vs $21 \%, \mathrm{p}=0.013)$. In the early cohort, the infundibulum was preserved in 15 patients $(75 \%)$. In the remaining cases, the infundibulum was not identified and was likely sacrificed in a prior operation (3 patients) or was indeterminate on review of the operative report ( 2 patients). Conversely, in the late cohort, the infundibulum was only preserved in 2 patients $(9 \%)$ and was intentionally sacrificed in $16(70 \%)$, which was a statistically significant difference between cohorts $(\mathrm{p}<0.001)$. In the remaining cases in the late cohort, the infundibulum was not identified and likely sacrificed in a prior operation (3 patients) or was indeterminate on review of the operative report (2 patients). Of the total 17 patients with infundibulum preservation, preoperative anterior pituitary function was normal in 6 patients and partial hypopituitarism was present in 8 patients. After surgery with infundibulum preservation, of the 6 patients with normal anterior pituitary function, 5 remained with normal function and 1 developed panhypopituitarism. Of the 8 patients with preoperative partial hypopituitarism, 4 remained stable and 4 developed further hypopituitarism. Of these 17 patients, preoperative DI was absent in 15. Postoperatively, 3 (20\%) of these patients developed permanent DI, whereas posterior pituitary function was preserved in 15 (80\%). The availability of preoperative BMI data in the early cohort was limited. Therefore, change in BMI between the most recent follow-up and preoperative state was only determined in 26 patients ( 5 early and 21 late cohort). The mean rate of BMI increase was 3.1. Of the 26 patients, $15(58 \%)$ had a BMI increase of $>2$ and $7(27 \%)$ had a BMI increase $>5$. 
TABLE 5. Postoperative endocrine function outcome

\begin{tabular}{|c|c|c|c|c|}
\hline $\begin{array}{l}\text { Endocrine Function } \\
\text { Outcome }\end{array}$ & Total & $\begin{array}{c}\text { Early } \\
(n=20)\end{array}$ & $\begin{array}{l}\text { Late } \\
(n=23)\end{array}$ & $\begin{array}{c}p \\
\text { Value }\end{array}$ \\
\hline \multicolumn{5}{|l|}{ Anterior pituitary function* } \\
\hline $\begin{array}{l}\text { Normal endocrine func- } \\
\text { tion }\end{array}$ & $6(15 \%)$ & $5(28 \%)$ & $1(4 \%)$ & 0.070 \\
\hline $\begin{array}{l}\text { Stable partial hypopitu- } \\
\text { itarism }\end{array}$ & $5(12 \%)$ & $4(22 \%)$ & $1(4 \%)$ & 0.150 \\
\hline Stable panhypopituitarism & $10(24 \%)$ & $4(22 \%)$ & $6(26 \%)$ & - \\
\hline $\begin{array}{l}\text { Partial to panhypopitu- } \\
\text { itarism }\end{array}$ & $10(24 \%)$ & $4(22 \%)$ & $6(26 \%)$ & - \\
\hline $\begin{array}{l}\text { Normal to panhypopitu- } \\
\text { itarism }\end{array}$ & $10(24 \%)$ & $1(6 \%)$ & $9(39 \%)$ & 0.025 \\
\hline \multicolumn{5}{|l|}{ DIt } \\
\hline None & $8(19 \%)$ & $6(32 \%)$ & $2(9 \%)$ & 0.112 \\
\hline Transient only & $10(24 \%)$ & $7(37 \%)$ & $3(13 \%)$ & 0.144 \\
\hline Stable permanent & $6(14 \%)$ & $2(11 \%)$ & $4(17 \%)$ & 0.673 \\
\hline New permanent & $18(43 \%)$ & $4(21 \%)$ & $14(61 \%)$ & 0.013 \\
\hline \multicolumn{5}{|l|}{ Infundibulum status } \\
\hline Preserved & $17(40 \%)$ & $15(75 \%)$ & $2(9 \%)$ & $<0.001$ \\
\hline Sacrificed & $16(37 \%)$ & 0 & $16(70 \%)$ & $<0.001$ \\
\hline $\begin{array}{l}\text { Not identified/prior } \\
\text { sacrifice } \neq\end{array}$ & $6(14 \%)$ & $3(15 \%)$ & $3(13 \%)$ & - \\
\hline Indeterminate & $4(9 \%)$ & $2(10 \%)$ & $2(9 \%)$ & - \\
\hline \multicolumn{5}{|c|}{$\begin{array}{l}\text { * Data not available in } 2 \text { patients }(5 \%) \text {. } \\
\text { † Data not available in } 1 \text { patient. Five patients (12\%) had a preoperative his- } \\
\text { tory of polydipsia and polyuria without hypernatremia or a known diagnosis of } \\
\text { DI and were counted as having normal preoperative function. Three patients } \\
\text { had permanent DI and } 2 \text { had transient only DI. } \\
\text { If the infundibulum was not identified intraoperatively according to operative } \\
\text { report and the patient had a history of resection and preoperative panhypopi- } \\
\text { tuitarism, it was believed that the infundibulum was likely sacrificed in the prior } \\
\text { operation. }\end{array}$} \\
\hline
\end{tabular}

Overall mean and median follow-up durations were 40.4 and 29 months, respectively (Table 6). As expected, the mean follow-up duration was significantly longer in the early cohort (53.4 vs 29.2 months, $\mathrm{p}=0.024$ ). Twelve patients required adjuvant fractionated stereotactic radio- therapy for incomplete resection. Although the difference in follow-up durations renders comparison difficult, 6 patients (33\%) in the early cohort developed tumor progression or recurrence compared with $4(19 \%)$ in the late cohort (2 patients in each group had fewer than 3 months of follow-up). The overall mean time to progression/recurrence was 17.5 months. The treatment of recurrence included multimodality therapies including Ommaya reservoir placement, intracystic P32 isotope, reoperation, and stereotactic radiotherapy.

\section{Discussion}

\section{Study Interpretation}

This study demonstrates a significant learning curve in endoscopic endonasal resection of craniopharyngiomas. There was a statistically significant reduction in major neurological complications and postoperative CSF leaks in the late cohort. In addition, there was a large statistically significant increase in the proportion of patients discharged to home rather than to a rehabilitation or nursing facility in the late cohort. There was also a large statistically significant increase in the rate of GTR in the late cohort. This may, in part, reflect a shift in practice with regard to stalk management, as there was a significant increase in the proportion of stalk sacrifice in the late cohort. However, this is unlikely the sole explanation, as one would expect that a small rind of tumor left adjacent to the stalk in attempt to preserve it would convert a GTR to a NTR $(>95 \%)$. However, we saw a large decrease in STR as well (40\% to $13 \%)$, but this was not statistically significant $(\mathrm{p}=0.078)$. As expected, the increased frequency of stalk sacrifice in the late cohort was accompanied by a significant increase in the rate of new postoperative endocrinopathy including panhypopituitarism and DI.

\section{Learning Curve in Craniopharyngioma Surgery}

There currently exists no evidence regarding the learning curve for endoscopic endonasal craniopharyngioma surgery. Prior studies evaluating the learning curve in endoscopic endonasal pituitary surgery have yielded mixed results. Sonnenburg et al. evaluated their results with pi-

TABLE 6. Tumor control

\begin{tabular}{lllcc}
\hline \multicolumn{1}{c}{ Factor } & \multicolumn{1}{c}{ Total } & Early $(\mathrm{n}=20)$ & Late $(\mathrm{n}=23)$ & $\mathrm{p}$ Value \\
\hline Adjuvant radiotherapy for STR/NTR & $12(28 \%)$ & $7(35 \%)$ & $5(22 \%)$ & 0.334 \\
\hline Recurrence/progression* & $10(26 \%)$ & $6(33 \%)$ & $4(19 \%)$ & 0.465 \\
\hline Mean time to recurrence/progression (mos) & 17.5 & 16.7 & 18.8 & 0.882 \\
\hline Treatment of recurrence/progression & & & & - \\
\hline$\quad$ Ommaya reservoir & 5 & 4 & 1 & - \\
\hline Intracystic P32 & 3 & 3 & 0 & - \\
\hline Reoperation & 4 & 2 & 2 & - \\
\hline$\quad$ Radiotherapy (FSRT) & 5 & 3 & 2 & - \\
\hline$\quad$ Observed & 1 & 0 & 1 & - \\
\hline Overall follow-up duration in mos: mean, median (range) & $40.4,29(1-115)$ & $53.4,67(1-115)$ & $29.2,23(1-74)$ & 0.024 \\
\hline
\end{tabular}

FSRT = fractionated stereotactic radiotherapy.

* Two patients from each cohort (4 total) did not have at least 3 months of follow-up and were excluded. 
tuitary surgery and observed no evidence for a learning curve. ${ }^{33}$ Other studies have demonstrated evidence for learning curve, with varying estimates of the number of cases needed to advance beyond the learning curve. One study demonstrated that complications decreased after approximately 18-34 cases. ${ }^{30}$ Another study demonstrated significant improvement in visual outcome and operating time after 50 endoscopic endonasal pituitary cases. ${ }^{18}$ It would seem self-evident that there would be a learning curve in expanded endonasal cranial base procedures in which the depth of surgical field is increased and the lesions are more intimately associated with critical neurovascular structures ${ }^{31,32}$ However, there is a paucity of evidence to demonstrate this learning curve and provide appropriate recommendations. One prior study demonstrated a learning curve in endoscopic endonasal chordoma resection with regard to GTR rates. In this study of 60 cases, the GTR rate progressively increased from $47 \%$ in the first 15 cases to $93 \%$ in the last 15 cases. $^{17}$

Our data clearly demonstrate an improvement in oncological outcomes as well as nonendocrine complication avoidance with increased experience using the endonasal endoscopic approach. To expedite surgical mastery of the procedure and allow for rapid progression along this learning curve, we have identified several key nuances in endonasal endoscopic craniopharyngioma surgery. Surgical judgment remains paramount, however, and the goals of surgery must be assessed on a case-by-case basis as improvements in extent of resection and visual outcomes may come at the expense of increased postoperative endocrine dysfunction.

Optimizing visual outcomes is one of the key end points of successful craniopharyngioma surgery. One of the primary advantages of the endoscopic endonasal approach is the direct visualization of the optic apparatus perforator vessels that arise off the superior hypophyseal arteries. While sacrifice of 1 or 2 smaller perforating branches may not necessarily result in vision loss, every attempt should be made to preserve each vessel when possible. During initial arachnoidal dissection, a plane between the left and right superior hypophyseal perforating branches is created and developed with a microdissector, sweeping the arachnoid from inferior to superior and from medial lateral, to mobilize the optic apparatus perforators toward the optic chiasm. From a transcranial approach, these perforators often cannot be adequately visualized, and a prior meta-analysis demonstrated that better postoperative visual outcome was achieved with the endoscopic endonasal approach than with transcranial approaches. ${ }^{15}$

The second nuance in successful craniopharyngioma surgery is the prevention of ischemic injury, which can be one of the most devastating complications associated with removal of a benign tumor. Numerous perforators exist in the suprasellar region and interpeduncular fossa, including the medial lenticulostriate vessels and the recurrent artery of Heubner arising from the anterior cerebral artery and/or anterior communicating artery, lateral lenticulostriate vessels arising from the $\mathrm{M}_{1}$ branch of the middle cerebral artery, and the thalamic perforators arising from the posterior communicating artery and/or posterior cerebral artery. Avoidance of primary direct injury requires steadfast adherence to the policy that resection of the tumor capsule must be performed under direct visualization and with sharp dissection. Avoidance of any temptation to pull or perform blind dissection is critical to minimize vascular injury. Furthermore, secondary injury related to immediate or delayed vasospasm has been reported after craniopharyngioma surgery as well. ${ }^{22,28,29}$ Vasospasm may be related to subarachnoid hemorrhage caused by tumor dissection. However, it has also been hypothesized that the caustic nature of cystic craniopharyngioma fluid may also result in vasospasm. An experimental model with rat femoral arteries has demonstrated that direct contact of the vessel with craniopharyngioma cystic fluid induces arterial vasospasm..$^{13}$ Therefore, the craniopharyngioma cyst must be entered in a controlled fashion. A small opening is created in the cyst wall with simultaneous aspiration at the puncture site to avoid spillage of cyst contents into the subarachnoid space. Prevention of cystic fluid spillage into the subarachnoid space and/or third ventricle may also help decrease the likelihood of postoperative communicating hydrocephalus, CSF leak, aseptic meningitis, and possibly even distant ectopic seeding of the tumor. ${ }^{4}$

As stated previously, appropriate judgment in regard to the extent of surgical resection is also a critical nuance that can greatly impact outcome. When dissecting tumor from the walls of the hypothalamus, a gliotic plane can often be identified and used to enable safe tumor removal. However, occasionally tumor appears invasive or excessively adherent to the hypothalamus and prudent judgment is required as to whether residual tumor must be left behind (Figs. 1 and 2). Additionally, the nature of the craniopharyngioma capsule is such that it is often very adherent to the optic chiasm or perforating vessels. There is an increasing body of evidence demonstrating that long-term tumor control rates may be similar between GTR alone and STR followed by adjuvant radiotherapy. ${ }^{34}$ Therefore, GTR at the expense of increased risk of hypothalamic injury, visual deterioration, or perforator injury is likely not justified.

In our series, we found a significant change in the management of tumor adherent to the infundibulum. Transinfundibular-type craniopharyngiomas incorporate the entire infundibulum in the center of the tumor, and complete resection cannot be achieved without sacrifice of the infundibulum ${ }^{14}$ (Fig. 3). However, other tumors may be parainfundibular (pre- or retroinfundibular), with the tumor arising eccentrically from the infundibulum (Fig. 4). In these cases, the tumor may be removed, with anatomical preservation of the infundibulum. However, functional preservation does not always correlate with anatomical preservation, and the impact of hypopituitarism must be weighed against the risk of tumor recurrence. Furthermore, one must consider that the use of adjuvant radiotherapy may itself induce hypopituitarism in cases of functional infundibulum preservation. Finally, in cases of planned STR or NTR due to adherence of the tumor to neurovascular structures, the added morbidity associated with infundibulum sacrifice may not be worth the limited additional oncological benefit.

One of the last important aspects of the learning curve in endoscopic endonasal craniopharyngioma surgery pertains to nuances in cranial base reconstruction. In our 


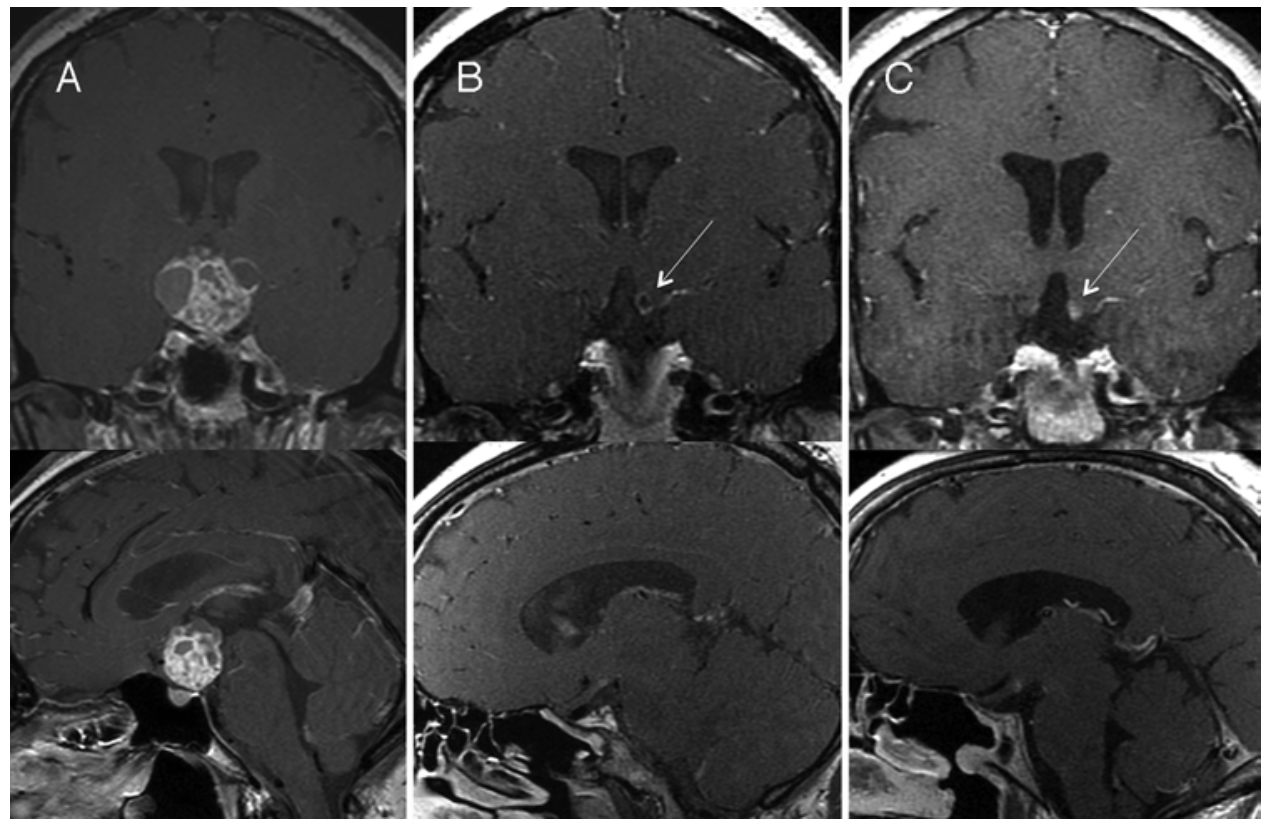

FIG. 1. Example of hypothalamic adherence. A: Preoperative coronal (upper) and sagittal (lower) T1-weighted (T1W) MR images with Gd. B: Postoperative coronal (upper) and sagittal (lower) T1W MR images demonstrating a small residual tumor, which, intraoperatively, was very adherent to the left hypothalamus. This was treated with fractionated stereotactic radiotherapy (FSRT). C: Five-year postoperative coronal (upper) and sagittal (lower) T1W MRI with Gd demonstrating stable residual tumor.

series, 6 of the CSF leaks occurred in the first 12 cases, prior to the use of nasoseptal flaps, which have been employed since 2007 at our institution. In addition, 2 of these 12 cases were purely infradiaphragmatic tumors, in which oxidized cellulose onlay alone was used for reconstruction with no postoperative CSF leak. In the last 31 cases since 2007 we have used an inlay/onlay fascia lata "button" re- construction followed by nasoseptal flap placement. ${ }^{21}$ This technique resulted in $1 \mathrm{CSF}$ leak in the 8 cases in which it was used in the early cohort. Subsequently, only $1 \mathrm{CSF}$ leak occurred in the 23 cases of the late cohort.

\section{Limitations}

There are several important limitations in this study.
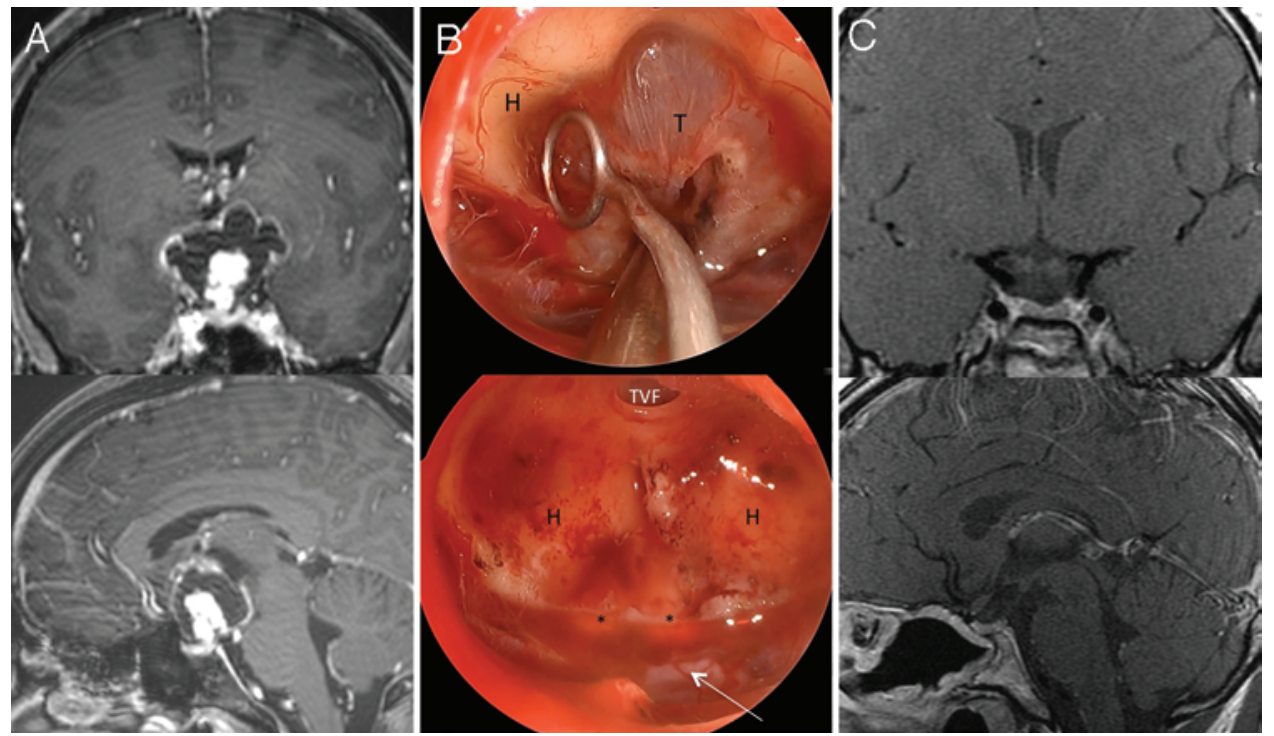

FIG. 2. Example of hypothalamic dissection. A: Preoperative coronal (upper) and sagittal (lower) T1W MR images with Gd. B: Intraoperative views: dissection of tumor $(\mathrm{T})$ from the right hypothalamus $(\mathrm{H})$ (upper) and appearance after complete resection of tumor from the surface of bilateral hypothalami $(\mathrm{H})$ (lower). Note that the third ventricle floor (TVF) has been displaced superiorly and is mostly intact. Mammillary bodies (asterisk) are visualized. Arachnoid of Liliequist membrane is intact and the basilar artery is visualized (white arrow). C: Postoperative coronal (upper) and sagittal (lower) T1W MR images with Gd demonstrating GTR. 


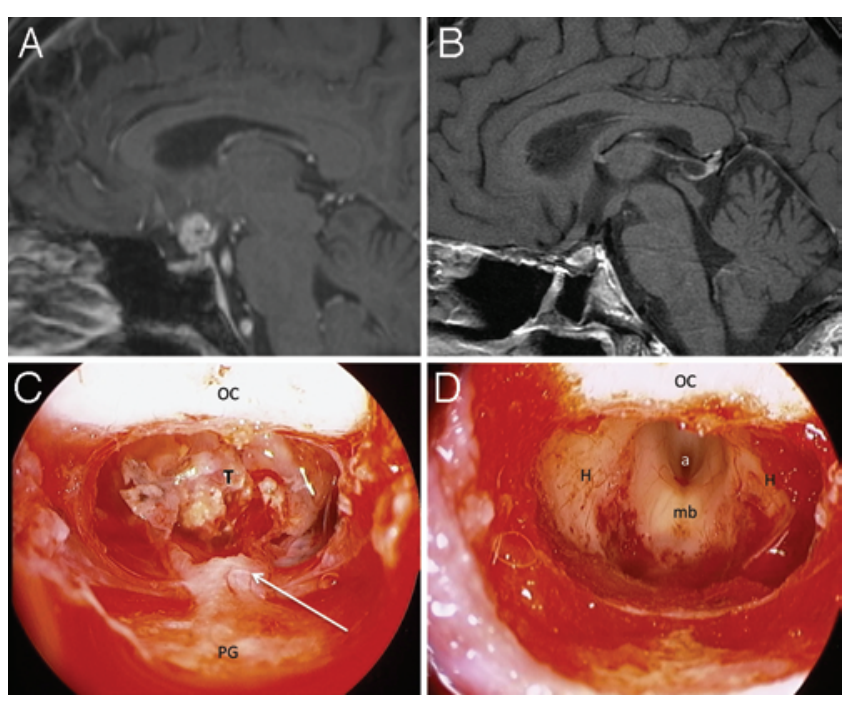

FIG. 3. Example of stalk sacrifice. A: Preoperative sagittal T1W MR image with $\mathrm{Gd}$ demonstrating solid craniopharyngioma in the retrochiasmatic space. B: Postoperative MR image demonstrating GTR and no recurrence 5 years after surgery. C: Intraoperative view demonstrating a transinfundibular-type tumor $(T)$ that is deeply invested in the infundibulum (white arrow). Sacrifice was required for complete tumor resection. D: Intraoperative view after complete resection. a = cerebral aqueduct; $\mathrm{H}=$ hypothalamus; $\mathrm{mb}=$ mammillary bodies; $\mathrm{OC}=$ optic chiasm; PG = pituitary gland

First, any time-based comparison will always be subject to bias because advances in scientific understanding, technology, anesthetic technique, and perioperative management may contribute to better outcome in more recently treated patient populations compared with historical controls. However, the relatively short time interval and lack of time gap between the early and late cohorts may minimize this effect. Second, while data must be categorized together into cohorts for statistical assessment, the learning curve is a continuous process and therefore it is difficult to make a true determination if our cutoff of 20 cases is sufficient to progress beyond the learning curve in endoscopic endonasal craniopharyngioma surgery. Finally, significant differences in the length of follow-up prevent adequate comparison of recurrence rates between the early and late cohorts.

\section{Patient Selection}

Anatomical variations and pathological features must be carefully studied preoperatively. Some tumors may be best addressed surgically via a transcranial or staged approach. Tumors extending lateral to the optic nerves or involving the $\mathrm{M}_{1}$ segment of the middle cerebral artery may be very difficult to safely access from an endonasal approach. In addition, optic chiasm anatomy must be carefully studied. Normal anatomy of the optic chiasm can vary from prefixed to postfixed in an anteroposterior axis, and low to high in a craniocaudal axis. ${ }^{20} \mathrm{~A}$ high, prefixed chiasm provides the largest endonasal surgical working corridor into the retrochiasmatic space. Conversely, a low postfixed chiasm may be unfavorable from an endonasal perspective. Most craniopharyngiomas arising from the distal two-thirds of the infundibulum tend to displace the optic chiasm superiorly. One must be cognizant of the tuberoinfundibular type of craniopharyngioma, which arises from the floor of the third ventricle and often pushes the optic chiasm anteroinferiorly. ${ }^{25,26}$ Such tumors may require retraction of the optic chiasm to access the tumor, which is associated with increased risk of visual deterioration.

\section{Conclusions}

Overall, the results of this study suggest that high rates of GTR and visual improvement or even normalization
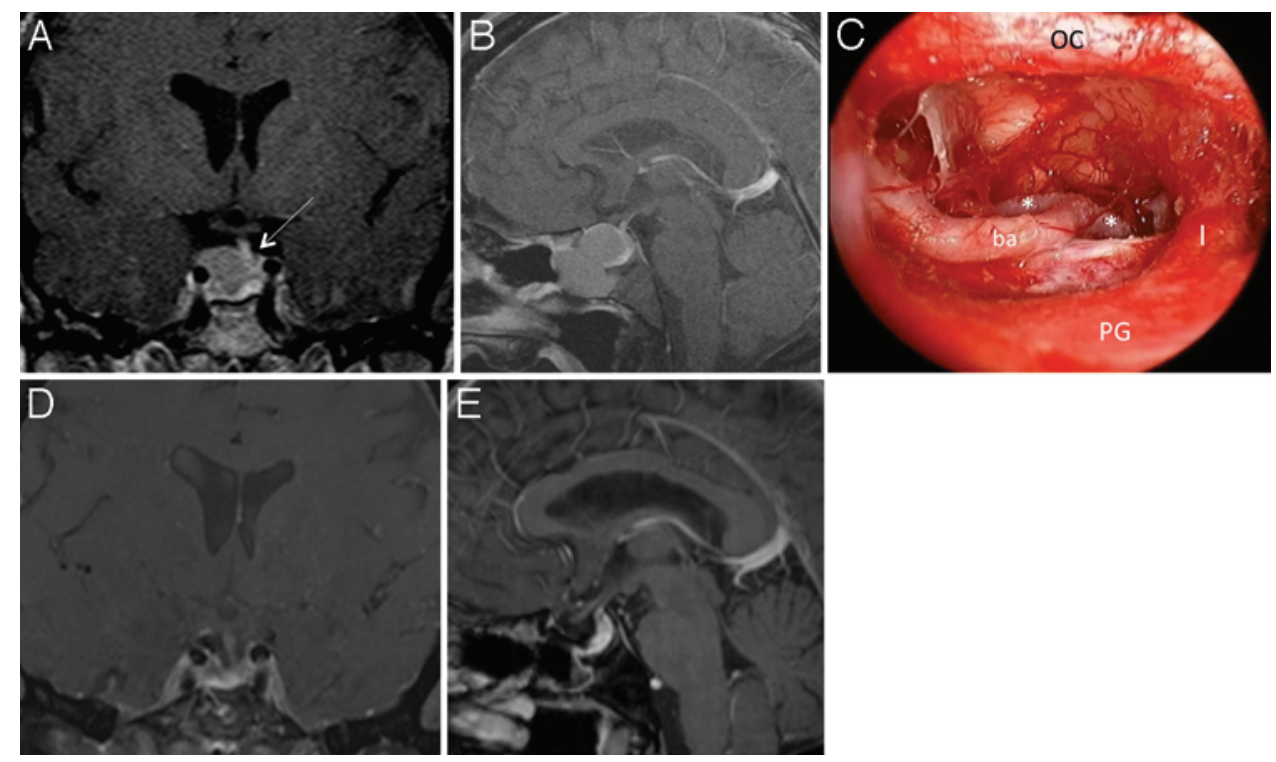

FIG. 4. Example of stalk preservation. Preoperative coronal (A) and sagittal (B) T1W MR images with Gd demonstrating cystic tumor within the right aspect of the sella with extension into the sphenoid sinus. Intraoperatively $(\mathbf{C})$, the tumor was dissected off the infundibulum (I). Postoperative coronal (D) and sagittal (E) T1W MR images with Gd demonstrating GTR with preservation of the infundibulum. ba = basilar artery; $O C=$ optic chiasm; $P G=$ pituitary gland; ${ }^{*}=$ posterior cerebral arteries. 
are achievable via the endoscopic endonasal approach for craniopharyngioma resection. However, we have demonstrated that a learning curve clearly exists with regard to the extent of tumor resection and nonendocrine morbidity. After 20 cases, we identified a significant decrease in major neurological complications as well as a significant increase in discharge to home status. Although there was a large decrease in the rate of postoperative CSF leak, this was largely attributable to early cases prior to the routine use of vascularized nasoseptal flaps. There was a significant increase in new panhypopituitarism and DI, which is attributable to more frequent intentional stalk sacrifice in the late cohort. Rates of GTR significantly increased over time as well, which may also be partially attributable to the shift in infundibulum management from preservation to sacrifice.

\section{References}

1. Barkhoudarian G, Laws ER: Craniopharyngioma: history. Pituitary 16:1-8, 2013

2. Campbell PG, McGettigan B, Luginbuhl A, Yadla S, Rosen M, Evans JJ: Endocrinological and ophthalmological consequences of an initial endonasal endoscopic approach for resection of craniopharyngiomas. Neurosurg Focus 28(4):E8, 2010

3. Cavallo LM, Frank G, Cappabianca P, Solari D, Mazzatenta D, Villa A, et al: The endoscopic endonasal approach for the management of craniopharyngiomas: a series of 103 patients. J Neurosurg 121:100-113, 2014

4. Clark SW, Kenning TJ, Evans JJ: Recurrent ectopic craniopharyngioma in the sylvian fissure thirty years after resection through a pterional approach: a case report and review of the literature. Nagoya J Med Sci 77:297-306, 2015

5. Cushing H: The craniopharyngiomas, in Intracranial Tumors. Notes upon a series of two thousand verified cases with surgical mortality percentages pertaining thereto. Springfield, IL: Charles C. Thomas, 1932, pp 93-98

6. DiPatri AJ Jr, Prabhu V: A history of the treatment of craniopharyngiomas. Childs Nerv Syst 21:606-621, 2005

7. Elliott RE, Hsieh K, Hochm T, Belitskaya-Levy I, Wisoff J, Wisoff JH: Efficacy and safety of radical resection of primary and recurrent craniopharyngiomas in 86 children. $\mathbf{J}$ Neurosurg Pediatr 5:30-48, 2010

8. Evans JJ, Kenning TJ: Endoscopic resection of craniopharyngiomas, in Evans JJ, Kenning TJ (ed): Craniopharyngiomas: Comprehensive Diagnosis, Treatment, and Outcome. Waltham, MA: Academic Press, 2014

9. Fatemi N, Dusick JR, de Paiva Neto MA, Malkasian D, Kelly DF: Endonasal versus supraorbital keyhole removal of craniopharyngiomas and tuberculum sellae meningiomas. Neurosurgery 64 (5 Suppl 2):269-286, 2009

10. Gardner PA, Prevedello DM, Kassam AB, Snyderman CH, Carrau RL, Mintz AH: The evolution of the endonasal approach for craniopharyngiomas. J Neurosurg 108:10431047,2008

11. Gerganov V, Metwali H, Samii A, Fahlbusch R, Samii M: Microsurgical resection of extensive craniopharyngiomas using a frontolateral approach: operative technique and outcome. J Neurosurg 120:559-570, 2014

12. Hofmann BM, Höllig A, Strauss C, Buslei R, Buchfelder M, Fahlbusch R: Results after treatment of craniopharyngiomas: further experiences with 73 patients since 1997. J Neurosurg 116:373-384, 2012

13. Kamal R, Jindal A, Suri A, Mahapatra AK: Effect of craniopharyngioma fluid on femoral vessels of rat. Neurol Res 21:796-798, 1999
14. Kassam AB, Gardner PA, Snyderman CH, Carrau RL, Mintz AH, Prevedello DM: Expanded endonasal approach, a fully endoscopic transnasal approach for the resection of midline suprasellar craniopharyngiomas: a new classification based on the infundibulum. J Neurosurg 108:715-728, 2008

15. Komotar RJ, Starke RM, Raper DM, Anand VK, Schwartz TH: Endoscopic endonasal compared with microscopic transsphenoidal and open transcranial resection of craniopharyngiomas. World Neurosurg 77:329-341, 2012

16. Koutourousiou M, Gardner PA, Fernandez-Miranda JC, Tyler-Kabara EC, Wang EW, Snyderman CH: Endoscopic endonasal surgery for craniopharyngiomas: surgical outcome in 64 patients. J Neurosurg 119:1194-1207, 2013

17. Koutourousiou M, Gardner PA, Tormenti MJ, Henry SL, Stefko ST, Kassam AB, et al: Endoscopic endonasal approach for resection of cranial base chordomas: outcomes and learning curve. Neurosurgery 71:614-625, 2012

18. Leach P, Abou-Zeid AH, Kearney T, Davis J, Trainer PJ, Gnanalingham KK: Endoscopic transsphenoidal pituitary surgery: evidence of an operative learning curve. Neurosurgery 67:1205-1212, 2010

19. Leng LZ, Greenfield JP, Souweidane MM, Anand VK, Schwartz TH: Endoscopic, endonasal resection of craniopharyngiomas: analysis of outcome including extent of resection, cerebrospinal fluid leak, return to preoperative productivity, and body mass index. Neurosurgery 70:110-124, 2012

20. Long H, Qi ST, Song Y, Pan J, Zhang XA, Yang KJ: Topographic variations of the optic chiasm and the pituitary stalk: a morphometric study based on midsagittal T2-weighted MR images. Surg Radiol Anat 36:775-781, 2014

21. Luginbuhl AJ, Campbell PG, Evans J, Rosen M: Endoscopic repair of high-flow cranial base defects using a bilayer button. Laryngoscope 120:876-880, 2010

22. Macdonald RL, Hoffman HJ: Subarachnoid hemorrhage and vasospasm following removal of craniopharyngioma. J Clin Neurosci 4:348-352, 1997

23. Mortini P, Losa M, Pozzobon G, Barzaghi R, Riva M, Acerno $\mathrm{S}$, et al: Neurosurgical treatment of craniopharyngioma in adults and children: early and long-term results in a large case series. J Neurosurg 114:1350-1359, 2011

24. O'Malley BW Jr, Grady MS, Gabel BC, Cohen MA, Heuer GG, Pisapia J, et al: Comparison of endoscopic and microscopic removal of pituitary adenomas: single-surgeon experience and the learning curve. Neurosurg Focus 25(6):E10, 2008

25. Pascual JM, Prieto R, Carrasco R: Infundibulo-tuberal or not strictly intraventricular craniopharyngioma: evidence for a major topographical category. Acta Neurochir (Wien) 153:2403-2426, 2011

26. Pascual JM, Prieto R, Carrasco R, Barrios L: Displacement of mammillary bodies by craniopharyngiomas involving the third ventricle: surgical-MRI correlation and use in topographical diagnosis. J Neurosurg 119:381-405, 2013

27. Patel KS, Raza SM, McCoul ED, Patrona A, Greenfield JP, Souweidane MM, et al: Long-term quality of life after endonasal endoscopic resection of adult craniopharyngiomas. J Neurosurg 123:571-580, 2015

28. Salunke P, Sodhi HB, Aggarwal A, Ahuja CK: Delayed cerebral vasospasm following surgery for craniopharyngioma. J Neurosci Rural Pract 4:107-109, 2013

29. Shida N, Nakasato N, Mizoi K, Kanaki M, Yoshimoto T: Symptomatic vessel narrowing caused by spontaneous rupture of craniopharyngioma cyst-case report. Neurol Med Chir (Tokyo) 38:666-668, 1998

30. Smith SJ, Eralil G, Woon K, Sama A, Dow G, Robertson I: Light at the end of the tunnel: the learning curve associated with endoscopic transsphenoidal skull base surgery. Skull Base 20:69-74, 2010

31. Snyderman C, Kassam A, Carrau R, Mintz A, Gardner P, 
Prevedello DM: Acquisition of surgical skills for endonasal skull base surgery: a training program. Laryngoscope 117:699-705, 2007

32. Snyderman CH, Fernandez-Miranda J, Gardner PA: Training in neurorhinology: the impact of case volume on the learning curve. Otolaryngol Clin North Am 44:1223-1228, 2011

33. Sonnenburg RE, White D, Ewend MG, Senior B: The learning curve in minimally invasive pituitary surgery. Am J Rhinol 18:259-263, 2004

34. Yang I, Sughrue ME, Rutkowski MJ, Kaur R, Ivan ME, Aranda D, et al: Craniopharyngioma: a comparison of tumor control with various treatment strategies. Neurosurg Focus 28(4):E5, 2010

\section{Disclosures}

Dr. Evans reports being a consultant for Stryker and receiving royalties from Mizuho for surgical instrument development. Dr. Kshettry reports being a consultant for Medprin.

\section{Author Contributions}

Conception and design: Evans, Kshettry. Acquisition of data: Kshettry, Do, Elshazly. Analysis and interpretation of data: Evans, Kshettry, Do, Farrell. Drafting the article: Kshettry. Critically revising the article: all authors. Reviewed submitted version of manuscript: all authors. Approved the final version of the manuscript on behalf of all authors: Evans. Statistical analysis: Kshettry. Study supervision: Evans.

\section{Correspondence}

James J. Evans, Center for Minimally Invasive Cranial Base Surgery and Endoscopic Neurosurgery, Thomas Jefferson University Hospital, 909 Walnut St., Philadelphia, PA 19107. email: james. evans@jefferson.edu. 